\title{
Análise comparativa dos aspectos gráficos e editoriais das revistas Chanaan e Vida Capichaba
}

\author{
Comparative analysis of graphical and editorial aspects of Chanaan \\ and Vida Capichaba magazines
}

\author{
AZERÊDO, Júlia Sousa \\ Universidade Federal do Espírito Santo - UFES I juliazeredodi@gmail.com \\ FONSECA, Letícia Pedruzzi \\ Universidade Federal do Espírito Santo - UFES I leticia.fonseca @ufes.br
}

\begin{abstract}
Resumo
Este artigo apresenta o levantamento e a comparação dos aspectos gráficos e editoriais das revistas Chanaan (1936-1939) e Vida Capichaba (1923-1959). O estudo foi realizado com o recorte 1936 a 1939. As duas revistas representavam a sociedade capixaba durante sua circulação. Para obtenção dos resultados foi criada uma ficha de coleta de dados, que posteriormente foram tabulados e geraram gráficos que tornaram possíveis as análises. Foi descoberto que a Revista Vida Capichaba durante esse período era mais sóbria que a Chanaan, mantendo um padrão nos seus aspectos gráficos e não possuindo grandes experimentos nas páginas e posicionamentos de imagens e anúncios. Já a Chanaan variou consideravelmente sua mancha gráfica, sendo os experimentos uma das características mais marcantes da revista. Além do contraste gráfico entre elas, a diferença mais marcante foi o conteúdo publicado, já que a Chanaan possuía um apelo político muito alto, diferente da Vida Capichaba.
\end{abstract}

Palavras Chave: Design. Memória gráfica. Revista. Chanaan. Vida capichaba.

\section{Abstract}

This paper presents the data collection and the comparison of graphical and editorial aspects between Chanaan magazine (1936-1939) and Vida Capichaba magazine (1923-1959). The material collected dates from 1936 to 1939. Both magazines portrayed the society of Espirito Santo (Brazilian state) while in publication. A data collection form was designed in order to gather reports. Afterwards, data was processed to enable the analysis. We discovered that, during that period of publication, Vida Capichaba had a cleaner design approach in comparison to Chanaan. Also, it followed graphic patterns and did not apply substantial changes in layout arrangement (images or advertising positioning, for instance). Chanaan, in turn, used to design with considerable variations in grid disposition - experimentation was one of its most striking characteristics. In addition to the graphic contrast between both magazines, the most remarkable difference lies in the content published, since Chanaan had a very high political appeal, which differs from Vida Capichaba.

Keywords: Design. Graphic memory. Magazine. Chanaan. Vida capichaba. 


\section{INTRODUC̣ÃO}

A década de 1930 foi marcada por intensas rupturas políticas onde temos como ponto de partida a ascensão de Getúlio Vargas no poder e uma série de renovações na estrutura política nacional e na constituição vigente. O Espírito Santo tinha como figura marcante o capitão João Punaro Bley, interventor entre 1930 e 1943, que representava os interesses de Getúlio Vargas contra os movimentos comunistas que chegavam ao Estado (ACHIAMÉ, 2010). Dentro desse cenário circulavam duas revistas que são objetos do atual estudo, a Revista Vida Capichaba (RVC) e a Chanaan.

A Vida Capichaba, circulou entre 1923 e 1959 em Vitória, Espírito Santo, e tinha inicialmente foco em matérias com teor informativo e textos literários, produzidos por meio de colaborações de intelectuais da época, se considerando retrato do povo. Teve alcance de público fora do estado e comercialização no Rio de Janeiro, São Paulo, Minas Gerais e outros estados (DUTRA; FONSECA; PACHECO, 2011).

Supõe-se que a revista Chanaan foi criada com o objetivo de concorrer com a revista Vida Capichaba, por interesses políticos (ACHIAMÉ, 2010). Chanaan circulou entre 1936 e 1939, em Vitória, Espírito Santo, com a direção de Carlos Madeira, ex-diretor da Vida Capichaba, do início ao fim da publicação.

Chanaan tinha um alto teor político e era direcionada para o público intelectual da época, contendo matérias em outras línguas como inglês e espanhol; incluía seções sobre poesias, literatura, filmes e música; tinha correspondentes internacionais, inclusive com matérias exclusivas com personalidades internacionais. Fazia grande uso de fotografias efotorreportagens que retratavam a vida social da capital e feitos políticos, principalmente de Punaro Bley, o então interventor do Estado. Atingiu público fora do Espírito Santo, e segundo informações da própria revista, teve circulação em capitais como Salvador, Belo Horizonte, Rio de Janeiro, São Paulo, e até mesmo fora do país.

Com base na descoberta que supostamente a Chanaan foi criada para competir com a Vida Capichaba, este estudo almeja comparar os dois impressos e verificar quais recursos a Chanaan usou para atrair o público e concorrer com a Vida Capichaba.

Pretende-se ainda compreender as possíveis similaridades e diferenças nos aspectos gráficos como a produção de anúncios, uso de imagem, encadernação, tipo de papel e de impressão, tipografia, letreiramento e caligrafia, formato, preço, circulação, dentre outros. 


\section{DESENVOLVIMENTO}

\subsection{Materiais e Métodos Utilizados na Pesquisa}

Foi realizada a digitalização do acervo, do mesmo período da Chanaan (1936-1939), da Revista Vida Capichaba na Biblioteca Estadual Levy Cúrcio e sua organização com nomenclatura padronizada por nome da revista, número de página, edição e ano: RVC_03_01_1936. O Laboratório de Desgin: História e Tipografia já possuía o acervo completo da Chanaan.

O próximo passo foi elaborar uma ficha de coleta de dados tendo como referência a ficha da revista Chanaan (AZERÊDO; TOSO; PEDRUZZI, 2015), para comparar dados específicos, como: tipo de publicação; mancha gráfica; relação do uso de imagem; quantidade e tipos de anúncios; e diferenças e relações entre uso de tipografia, letreiramento e caligrafia. Com a elaboração da primeira versão da ficha foram realizados diversos testes e ajustes. Todas as edições da RVC do período entre 1936 e 1939 tiveram fichas preenchidas.

A partir do preenchimento das fichas, iniciou-se a tabulação das informações para a organização e sistematização dos dados, que permitiu a geração de gráficos com resultados comparativos entre as duas revistas (DUTRA; FONSECA, 2014). Essa etapa da pesquisa gerou importantes resultados comparativos para a conclusão sobre as informações gráficas e possibilitou comparações entre as diferentes variáveis coletadas.

Foi realizada ainda revisão bibliográfica que abarcou o contexto histórico da década de 1930, período comparado no qual as revistas estavam inseridas.

\subsection{Editorial das Duas Revistas}

A revista Chanaan não possui muitos estudos sobre o seu projeto editorial, por isso a presente pesquisa teve um cuidado maior para descobrir esses aspectos, para então realizar a comparação com a Revista Vida Capichaba.

Na primeira edição, página 50, há um texto intitulado "Carta a Imprensa" em que é apresentada a intenção da revista:

“[...] tentar fazer alguma coisa de intercambio - é um dos paragraphos de seu programa de expansão cultural: levar para o Brasil o que o Espírito Santo tenha e possa mostrar e trazer para nós tudo o que de bom e bonito, interessante e curioso nos derem em troca [...]" (CHANAAN, 1936, p. 50). 
Sobre o nome da revista foi encontrada na primeira edição, página 21, um texto sobre o Valle do Chanaan, de José Cardoso, que cita a bíblia e a obra de Graça Aranha. O texto afirma que a cidade de Santa Tereza seria a realidade bíblica da terra prometida. E em outra edição novamente faz uma relação da bíblia e a terra prometida, com a obra de Graça Aranha e conclui com o trecho

\begin{abstract}
Agora, chegou a vez dos novos Hebreus da imprensa Capichaba, cheios de fé e carinho, alteando-se em montanhas, para decantar e divulgar pelo Brasil afora, conforme legenda da Revista, a divina Chanaan de esplendores e tradições honrosas, aquella que Graça Aranha há tantos anos encontrou ainda em roupagens judias, embora opulenta, vegetação dobrada e que, no entanto, mostrava que seria o symbolo do amor e da beleza entrelaçados no trabalho (CHANAAN, 1936, p. 67).
\end{abstract}

Com isso, conclui-se que a origem do nome da revista se refere ao grande sucesso de Graça Aranha, intitulada Canaã, publicada em 1902, a narrativa da obra gira em torno de imigrantes alemães em terras capixabas e retrata o Espírito Santo como um local sagrado.

Segundo informações, contidas na própria revista, ela alcançou público em diversas capitais brasileiras, na edição 15, segunda capa, traz uma lista com os representantes da revista fora da capital do Espírito Santo, com os seguintes lugares: Amazonas, Pará, Maranhão, Piauí, Ceará, Rio Grande do Norte, Paraíba, Pernambuco, Alagoas, Sergipe, Bahia, outras cidades do Espírito Santo, Rio de Janeiro, São Paulo, Paraná, Santa Catarina, Rio Grande do Sul, Minas Gerais, Goiás e Mato Grosso.

A revista também trazia diversos dados dos colaboradores da revista, na segunda capa da terceira edição esclarece que as seções da revista são fixas e com redatores fixos, que só era solicitado colaboração para temas específicos, mas que "acolherá toda aquella que se apresentar digna de seu público". Também trazia notas em relação a outras funções dentro da revista como os fotógrafos que eram frequentemente creditados.

Foram realizadas análises da representação de Bley na revista por ser algo frequente e acredita-se que a Chanaan foi criada com o intuito de apoiá-lo, levando em consideração o incentivo que o governo Vargas dava para outros periódicos para promover seu governo, provavelmente incentivava a publicação da Chanaan e assim divulgava as realizações de Bley no Estado.

Essa suposição da criação da revista foi percebida após identificar que durante o período de circulação da Chanaan em 16 edições aparecem fotografias e matérias do Bley só em atos políticos, fora as edições que fazem referência a ele ou sua família, que também aparecia frequentemente em matérias diversas. 
Em novembro de 1939, mesmo ano do fim da circulação da revista Chanaan, houve um incêndio na Imprensa Oficial do Espírito Santo, que provocou a perda e destruição de quase todos os equipamentos e do acervo da instituição. Até hoje não se sabe as causas do incêndio, mas, acredita-se que seja por um curto circuito nas instalações do prédio, que era bem precária e passava por reformas (MATTEDI, 2005). O fim da publicação da revista coincide com o incêndio do parque gráfico que a imprimia, portanto supõe-se que esse teria sido o motivo pelo qual a revista Channan encerrou sua trajetória.

Em relação à revista Vida Capichaba, durante o período comparado de 1936 a 1939, não apresentava grande quantidade de informações sobre os colaboradores da revista como na Chanaan. Porém, a partir da edição 451, durante esse período do recorte, começou a ser publicada uma seção intitulada "Galeria dos Colaboradores", que continha uma fotografia de um colaborador que escrevia na revista e um pequeno texto falando sobre ele. Também possuía informações sobre os fotógrafos, como o Mazzei que continha anúncio do seu trabalho com uma nota que ele também publicava na RVC, alguns desses fotógrafos também estavam presentes na Chanaan.

Durante esse período do recorte parecia ser frequente pessoas que faziam assinaturas da revista com falsos representantes, há notas que aparecem em algumas edições esclarecendo informações sobre os representantes no interior do Estado, e outras com o nome de todos os representantes.

Era frequente a promoção de concursos pela $R V C$, já na primeira edição do período estudado, 401, tem uma nota na página 14 dizendo que a capa daquela edição era da vencedora do 'Concurso Graça Infantil', em outras edições foram encontrados cupons para eleger a 'Miss Vitoria', eles iam acompanhados de instruções para enviar o voto à revista. Outros concursos encontrados foram o de 'Melhor bloco de carnaval de 1936', com instruções semelhantes para encaminhar o cupom, e o de 'Rainha dos estudantes capixabas de 1936'.

Em algumas edições foram encontradas notas solicitando aos leitores fotografias do carnaval, como na edição 404, página 05, e em outras uma nota informando que a revista publicava gratuitamente clichês de crianças, moças, vistas das localidades do Estado, festas, casamentos, etc., que era só encaminhar para a redação, aparece à primeira vez na edição 408, página 24. Essa grande proporção de comunicação direta com os leitores demonstra uma grande diferença no teor dos conteúdos publicados nas duas revistas, a Chanaan não fazia nada semelhante.

Na $R V C$, eram frequentes propagandas da própria revista e da sua oficina gráfica, indicando que aceitavam encomendas. Porém, não publicavam notas com elogios de outros impressos ou pessoas escrevendo sobre ela, como fazia frequentemente a Chanaan. 
A presença de Punaro Bley na revista Vida Capichaba foi notada com uma frequência muito inferior se comparada à forma como era retratado na Chanaan, contendo outro teor e sem tanto destaque. As matérias apenas faziam referência a atos políticos em que ele estava presente, não foi identificado nenhum político com grande destaque na revista.

A única edição, durante esse período, que teve um maior destaque para algum político foi na edição 456 em que a capa foi o presidente Getúlio Vargas.

\subsection{Comparação dos Aspectos Gráficos das Revistas Vida Capichaba e Chanaan}

A revista Chanaan possuía dois tipos de publicação, uma simples que era um mês em uma edição e outra dupla com dois meses na mesma edição, nesses 4 anos de publicação houve alguns meses que ficou sem publicar. Já a Revista Vida Capichaba era quinzenal no mesmo período de publicação da Chanaan, publicou dessa forma durante todo esse período comparado e não teve intervalos.

A Chanaan teve grande variação na quantidade de páginas de suas edições, alternando entre 40 e 90 páginas. A revista Vida Capichaba não possuía esse tipo de variação, oscilava entre 20 e 40 páginas e apenas em duas edições especiais de natal que chegaram a uma quantidade maior, com 68 páginas.

$\mathrm{Na}$ Chanaan foi predominante o uso de papel acetinado e encadernação tipo canoa provavelmente por ser mais simples, barata e rápida (AZERÊDO; TOSO; PEDRUZZI, 2015). Já a RVC, durante esse período, variou os papéis em qualidades diferentes, um papel melhor, que ainda hoje se mantém branco, contendo as fotografias, conteúdos de maior destaque, poesias e menções honrosas, e outro papel inferior, que ficou amarelado, para textos com menor destaque, pequenas ilustrações e anúncios. Não foi identificado o mesmo padrão na Chanaan em relação à disposição das matérias, seções, fotografias e anúncios nas diferenças de papel.

Nas duas revistas a impressão foi tipográfica do início ao fim, com imagens e alguns anúncios em clichê. $O$ formato da $R V C$ durante esse período variou entre $18 \times 26 \mathrm{~cm}$ e $23 \times 31 \mathrm{~cm}$, já a Chanaan entre $16,5 \mathrm{~cm} \times 23,5 \mathrm{~cm}$ e, um pouco maior, com $17,5 \mathrm{~cm} \times 26 \mathrm{~cm}$.

O preço da Chanaan variava entre $1 \$ 000$ e $2 \$ 000$ réis e a $R V C$, durante o período comparado, custava sempre $1 \$ 000$ e apenas em duas edições, $446 \mathrm{e}$ 492 , as que continham mais páginas e eram edições de natal, custou $2 \$ 000$. 


\subsection{Capas da Chanaan e RVC}

Nas capas da Chanaan a variação do tipo de imagem alternou entre fotografia, ilustração, fotomontagem e outra (comumente sendo uma junção entre fotografia e ilustração), sendo a maioria, com 68\%, de fotografias. Já as imagens das capas da RVC variaram entre fotografia e ilustração, sendo fotografia predominante com $71 \%$ das capas.

A tipologia da imagem das capas da Chanaan variou entre personalidades, pontos turísticos, datas comemorativas e outros, com os mais frequentes variando entre personalidades com $40 \%$ e pontos turísticos com $37 \%$. Nas capas da RVC foi mais frequente a presença de personalidades, totalizando $62 \%$ das edições, alternou também entre datas comemorativas, personalidades e outros, que em sua maioria eram ilustrações de ilustradores locais, com presença em $22 \%$ nas edições.

Figura 1 - Imagens das capas da revista Chanaan (edições 4, 20, 22/23 e 31).
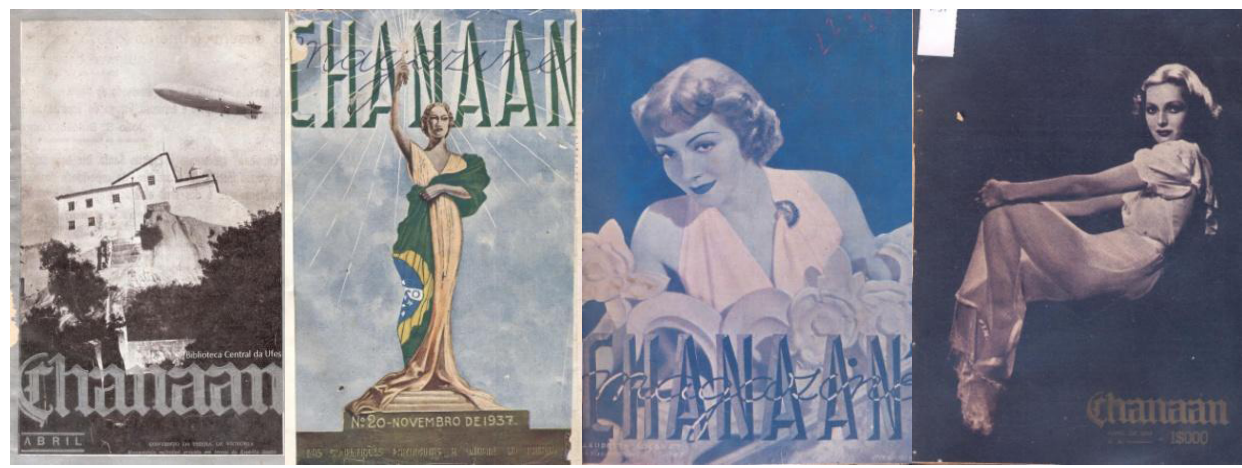

Fonte: Chanaan (1936, 1937, 1938, 1939).

Figura 2 - Imagens das capas da revista Vida Capichaba (edições 402, 403, 442 e 490).

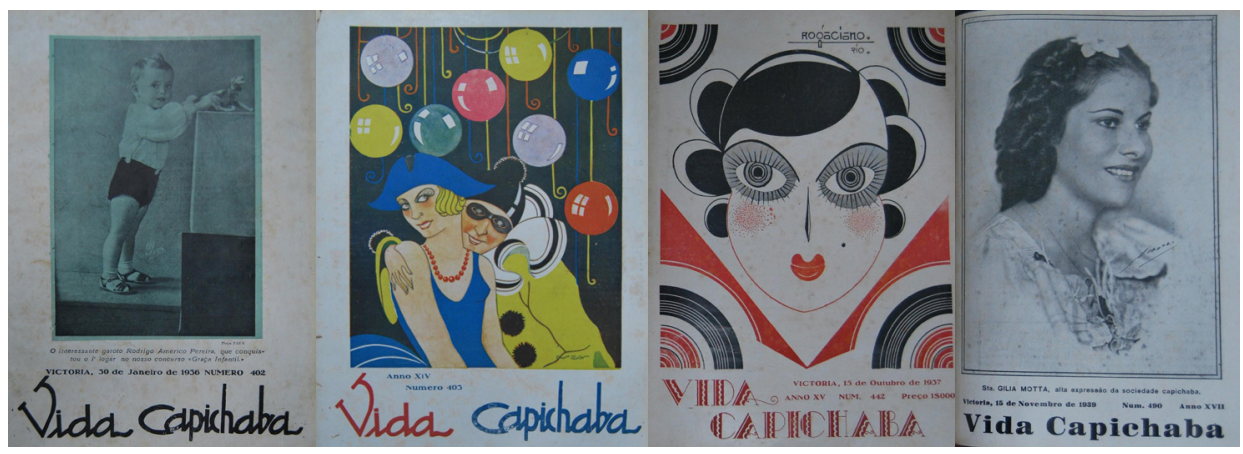

Fonte: Vida Capichaba (1936, 1937, 1939).

As personalidades encontradas com maior frequência nas capas da Chanaan variaram entre esposas ou filhas de políticos locais, pessoas da alta sociedade, como empresários, e políticos. Os pontos turísticos retratados eram 
de lugares do Estado. Com um teor diferente da Chanaan, que tinha forte apelo político, a RVC retratou as personalidades nas capas, que na maioria das vezes eram mulheres da sociedade ou crianças, chegando a ter um concurso intitulado Graça Infantil. Comumente apresentavam capas com datas comemorativas como carnaval, festa junina e natal, sendo essas, em sua maioria produzidas com ilustrações.

\subsection{Comparação da Mancha Gráfica}

A RVC, durante o período comparado, usava grid de duas ou três colunas com tamanhos similares, utilizava majoritariamente o alinhamento justificado, resultando em pouco espaço sem impressão, e ainda assim havia clara divisão dos conteúdos. Os únicos experimentos presentes na $R V C$ neste período foram na seção fixa Vida Capichaba e em algumas fotomontagens.

Figura 3 - Primeira imagem é um exemplo de como eram as páginas da RVC e as demais seções Vida Capichaba onde tinham algumas mudanças na mancha gráfica (edições 457, 407 e 430)

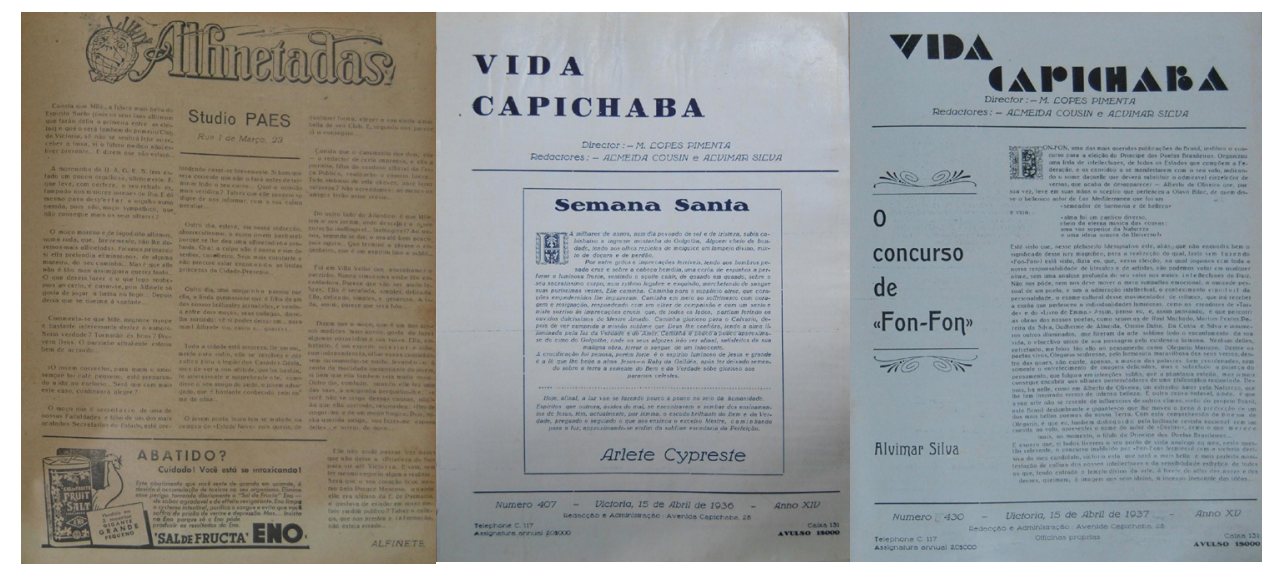

Fonte Vida Capichaba $(1938,1936,1937)$.

A mancha gráfica da Chanaan também era composta majoritariamente por duas ou três colunas com tamanhos próximos e texto justificado, porém com variações que ocorriam em seções fixas, matérias especiais, poesias, contos ou crônicas utilizando alinhamento à esquerda e experimentos gráficos, como colunas na diagonal (AZERÊDO; TOSO; PEDRUZZI, 2015). 
Figura 4 - As duas primeiras figuras são experimentos do alinhamento, à esquerda alinhamento com imagem no texto e no meio uso do alinhamento à esquerda. $A$ terceira figura representa a maioria das páginas, com as colunas com tamanhos próximos e texto justificado (edição 11/12, 21 e 29).
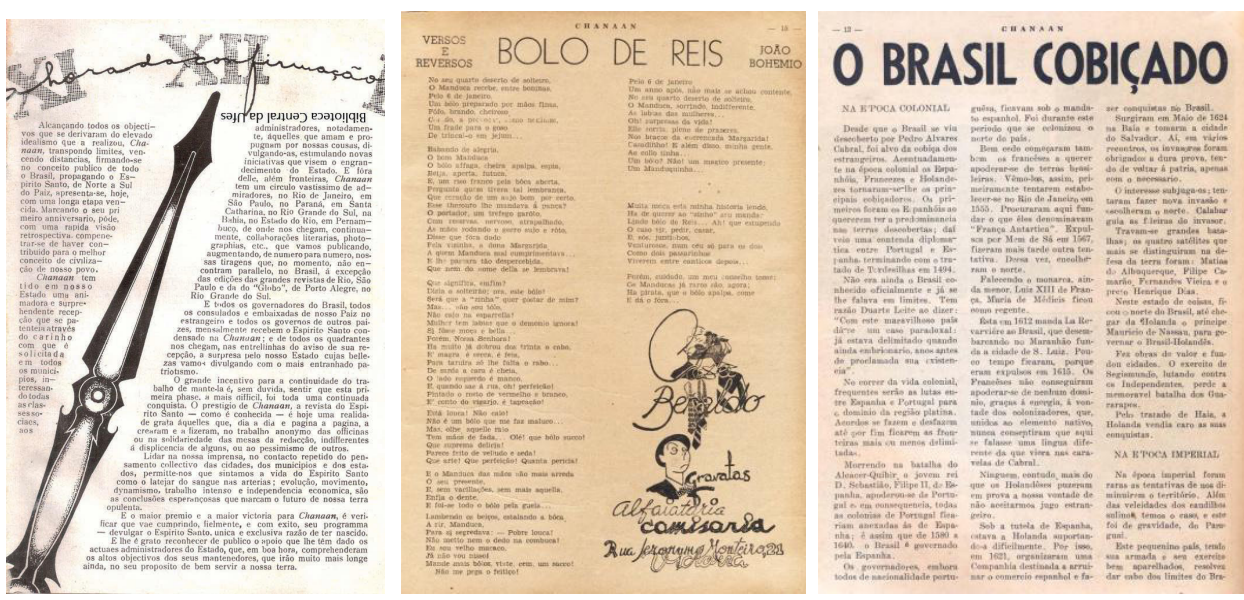

Fonte: Chanaan (1936, 1937, 1939).

Na comparação da quantidade de famílias tipográficas utilizadas nos textos, percebeu-se que a Chanaan teve uma variação maior que a RVC, variando de 1 a 4 famílias por edição, e a RVC tinha uma constância com uso de 2 famílias tipográficas, sendo uma delas com serifa e variando apenas no uso de itálico, bold e normal e na entrelinha, o que às vezes dava a impressão de que era uma tipografia diferente.

Figura 5 - Tipografias mais utilizadas ao longo das edições da Chanaan. À esquerda tipografia com serifa e à direita tipografia com terminal arredondado (edição 21 e19).

Houve um corre-corre apavorado. Cadeiras cahiam, copos partiam-se, e vozes sussurrantes ga guejavam pelos cantos, pávidas: - E' O Principe!
"Espadarte" marcou uma epopéa dos nossos escoteiros do mar, sob o commando de Eugenio Pellerano.

Fonte: Chanaan (1937).

Figura 6 - Tipografia mais utilizada ao longo das edições da Revista Vida Capichaba.

\section{Pequena, como as flores e como as joias, Vi- foria humana, de civilisação conquista dora e di- namica.}

Fonte: Vida Capichaba (1939).

Havia três formas de títulos de seções, dentre eles tipográfico, caligráfico e letreiramento. $\mathrm{Na}$ Chanaan o mais predominante foi o uso de letreiramento, com $51 \%$ nas edições e caligrafia e tipografia com $26 \%$ e $23 \%$, respectivamente. $\mathrm{Na}$ construção dos títulos das seções na RVC também foi predominante o 
letreiramento, com um pouco mais de uso que a Chanaan, presente em $78 \%$ das edições e, em quantidade menor, os títulos em tipografia com $16 \%$ e caligráfico com $6 \%$.

Figura 7 - Uso de caligrafia, título de seção Cartas para o meu namorado, presente em diversas edições, uso de letreiramento nos títulos das seções Internacionaes e tipografia nas seções Sports, presente em diversas edições, todas da Revista Chanaan.

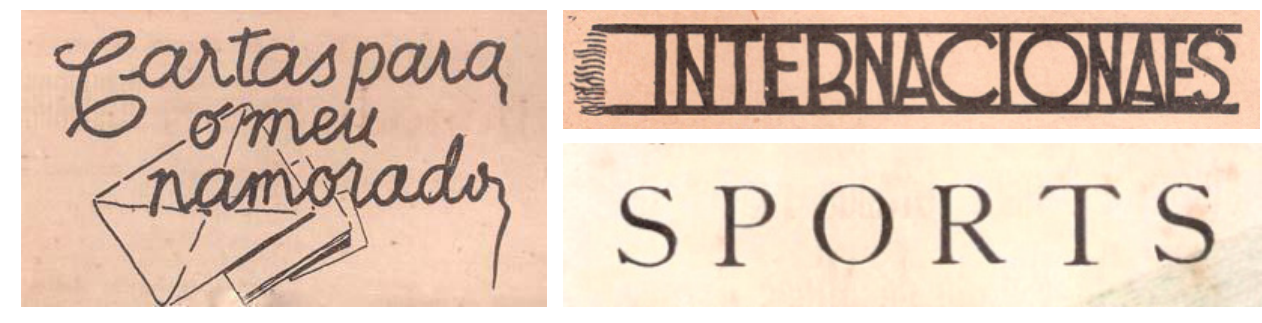

Fonte: Chanaan (1936).

Figura 8 - Uso de letreiramento nos títulos de seção da Revista Vida Capichaba, presente em diversas edições.

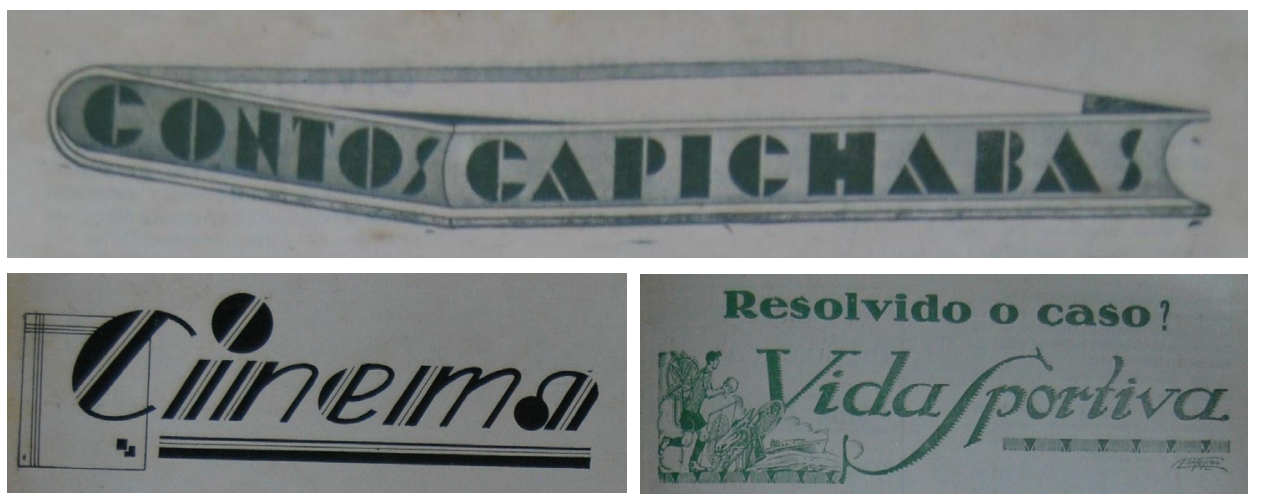

Fonte: Vida Capichaba (1923).

Era comum encontrar nas seções e matérias as assinaturas dos autores, variando entre tipográfica, caligráfica e letreiramento, assim como no título, e sendo predominante o uso de tipografia nas duas revistas, com $72 \%$ na RVC e $68 \%$ na Chanaan. RVC variou menos que a Chanaan, com $26 \%$ de caligrafia e $2 \%$ de letreiramento e Chanaan um pouco mais com 19\% de caligrafia e 13\% de letreiramento.

A análise dos títulos referentes às matérias diversas, poesias, contos e crônicas variaram entre letreiramento e tipografia, a Chanaan teve mais experimentações e variações entre elas que a RVC.

As legendas das imagens da Chanaan variaram entre base tipográfica e caligráfica. Havia variação no uso de tipografia, no entanto a mais utilizada era sem serifa e com terminal arredondado, mais uma vez na Chanaan houve uma variação maior no uso de tipografias e caligrafias, comparada a RVC. A RVC variou entre tipografia e letreiramento. 


\subsection{Anúncios Publicados nas Revistas}

Eram frequentes os anúncios presentes nas revistas, fazendo parte da identidade visual dos dois periódicos. A origem dos anunciantes da RVC era diversificada, sendo os mais frequentes do Espírito Santo, Rio de Janeiro e "outros" com lugares como o sul do país, teve também de São Paulo, nacionais e alguns que não foi possível identificar a origem. Na Chanaan foi predominante anúncios do Espírito Santo com $68 \%$ dos publicados nas revistas. Os demais eram dos mesmos locais que a RVC com a diferença de nos "outros" mais presença de anúncios da Bahia e de Minas Gerais.

Durante o período comparado, a Chanaan publicou mais anúncios nas revistas por edição do que a RVC. A Chanaan oscilava muito na quantidade de anúncios, como ter publicado 106 na primeira edição e 82 na segunda, isso foi frequente durante toda sua publicação. A RVC era constante até na quantidade de anúncios publicados, variando entre 20 e 30 anúncios por edição, as duas edições que chegaram a uma quantidade maior, como 60 anúncios, foram edições especiais de natal.

Além de tipografia, os anúncios tipográficos contavam com a presença de lettering e caligrafia em suas composições. Os presentes na Chanaan tinham frequentemente bordas como apelo visual, divididos entre simples, ornamentadas ou ausentes. Vale ressaltar que a borda era considerada simples por usar apenas o fio, porém eram realizadas composições com esses fios; já as bordas ornamentadas eram formadas por elementos como círculos, triângulos, tracejados com " $x$ " entre os traços, dentre outros. Os anúncios da Chanaan que não continham bordas não tinham fios que o separasse na página do texto, diferente da RVC que fazia uso desse recurso.

Figura 9 - Imagens de anúncios tipográficos com bordas ornamentadas da Revista Chanaan.
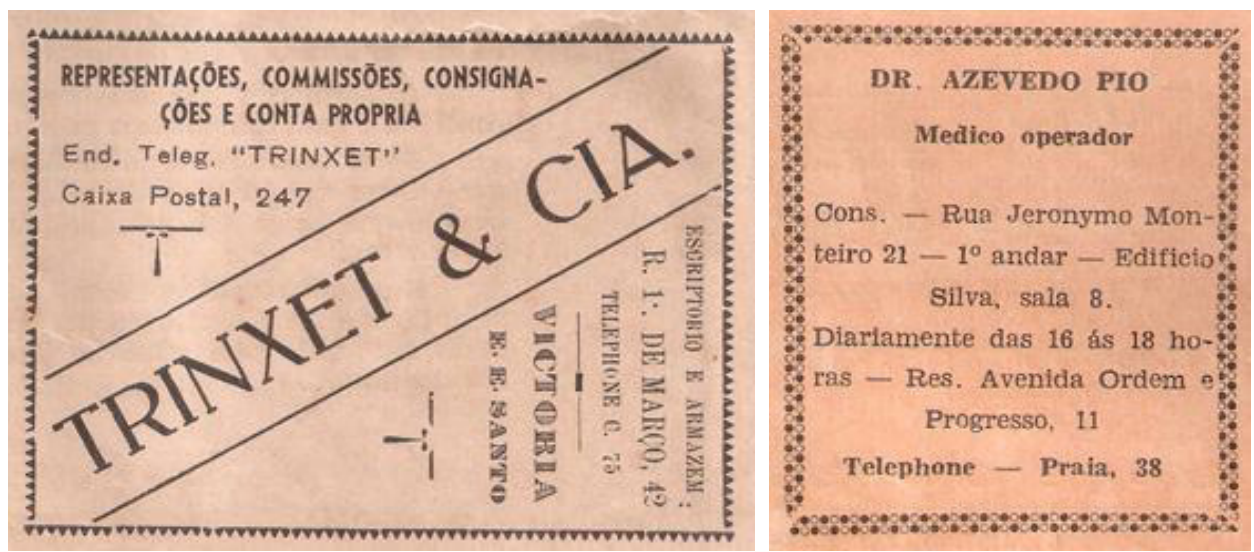

Fonte: Chanaan (1936).

Já os anúncios tipográficos da RVC não variaram muito em uso de borda, ou o anúncio não possuía ou ele era simples, poucos continham a borda ornamentada. 
Figura 10 - Imagem de anúncio tipográfico da Revista Vida Capichaba.

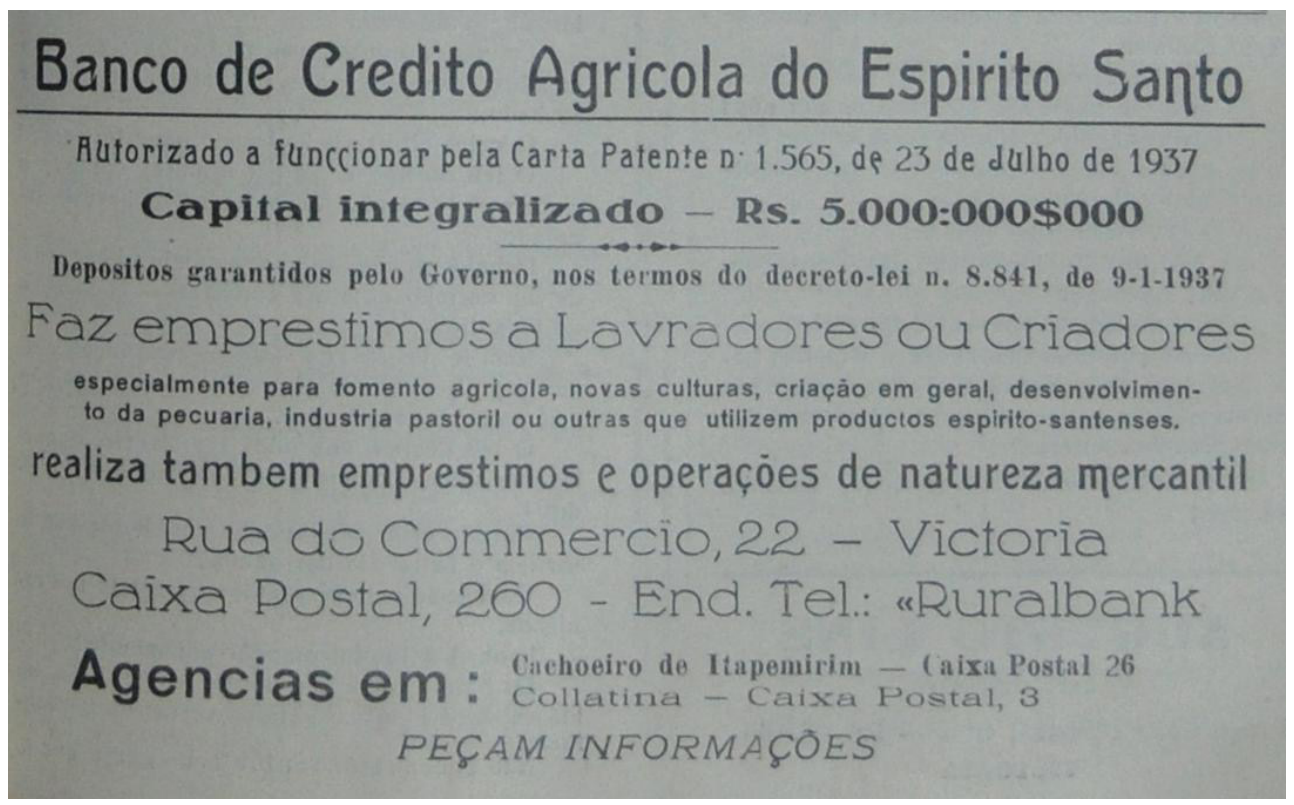

Fonte: Vida Capichaba (1938).

A ocupação desses anúncios nas páginas da Chanaan variava entre uma, duas ou três colunas, rodapé, cabeçalho, página inteira ou meia página, com os mais frequentes entre uma coluna e rodapé. Na RVC eles utilizavam com mais frequência em uma coluna, variando muito pouco entre duas colunas e rodapé, e esses anúncios comumente ficavam alinhados no grid, diferente da Chanaan.

Os anúncios imagéticos na Chanaan variavam entre ilustração pictórica, fotografia, quadrinhos e outros (que normalmente era uma mistura de ilustração com fotografia). As ilustrações pictóricas eram mais frequentes com $80 \%$ dos anúncios, em seguida vinha fotografia com $9,5 \%$, outros com $7 \%$ e em algumas edições possuíam anúncios em quadrinhos. Esses ocupavam com maior frequência uma e duas colunas, e a partir da décima terceira edição se tornou comum esses anúncios ocuparem a página inteira. Os imagéticos da RVC variaram entre ilustração pictórica, fotografia e quadrinhos, sendo ilustração pictórica em maior quantidade com $78 \%$ dos anúncios desse período. Quanto ao posicionamento desses anúncios variou entre uma coluna, 1/2 página e paginação, com uma coluna mais frequente com $83 \%$ dentre essas variações. 
Figura 11 - Anúncios imagéticos da Revista Chanaan, ilustração pictórica, fotografia e quadrinho, respectivamente (edições 1, 29 e 24)
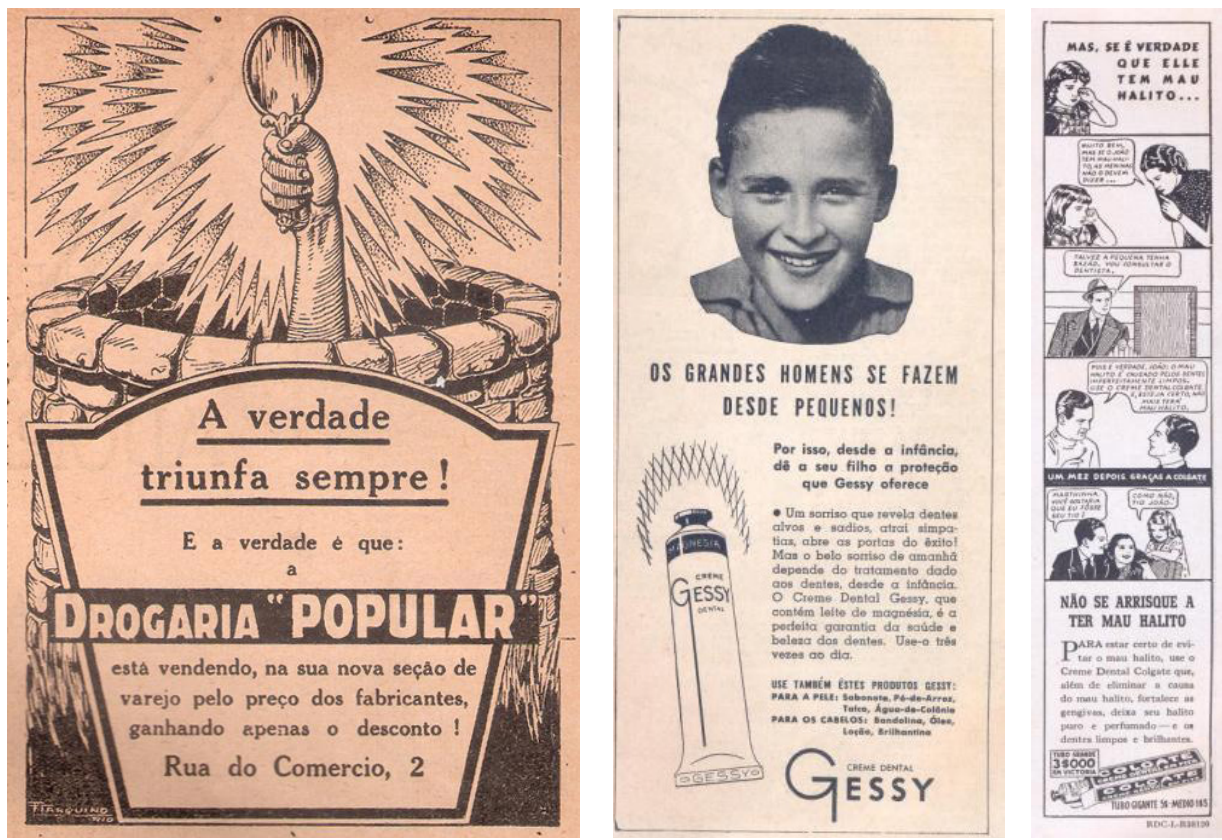

Fonte: Chanaan $(1936,1938,1939)$.

Figura 12 - Anúncios imagéticos da Revista Vida Capichaba (edições 452, 477 e 474).
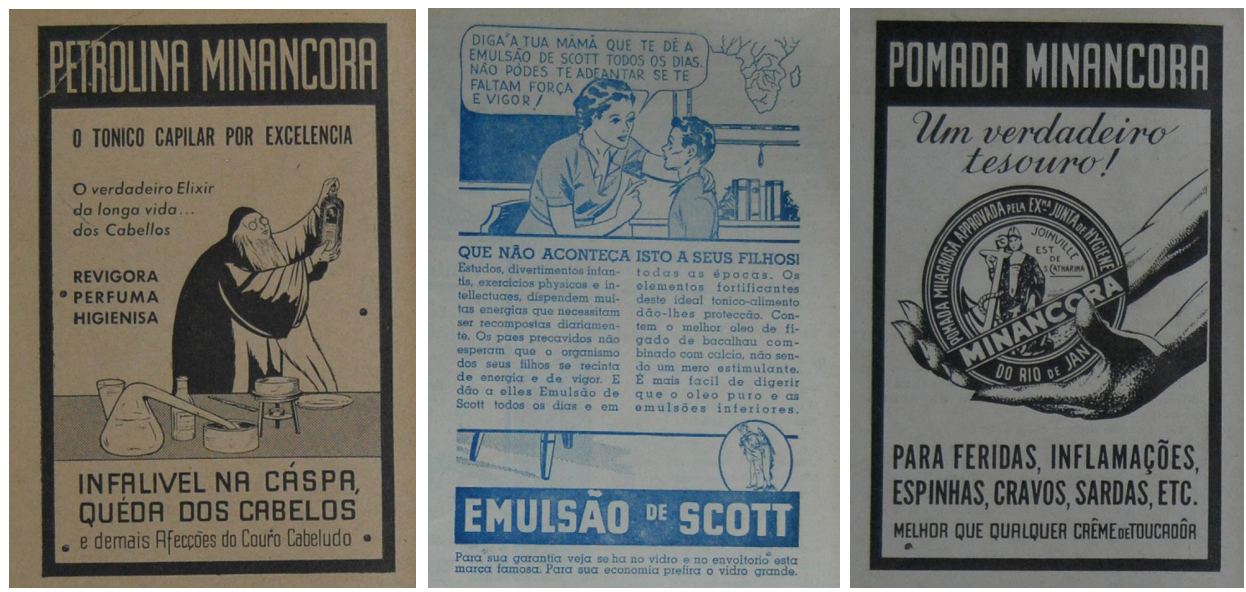

Fonte: Vida Capichaba $(1938,1939)$.

A revista Chanaan ainda possuía anúncios híbridos, em número menor, que continha imagem, porém o texto era o foco do anúncio, não eram todas as edições que o possuíam e quando tinha era apena um anúncio na edição. A maioria desses anúncios ocupou página inteira e os demais ficaram entre uma coluna ou meia página. $O$ tipo de imagem presente no anúncio variava entre ilustração pictórica e fotografia.

Também na Chanaan, continha ainda página de classificados, que predominavam anunciantes de médicos, clínicas e advogados. 
Figura 13 - Anúncio híbrido, presente na Revista Chanaan, considerado assim por conter além da imagem um longo texto. Classificados, que no início continha mais anunciantes e diminuiu no final da circulação (edições 3, 9 e 32).
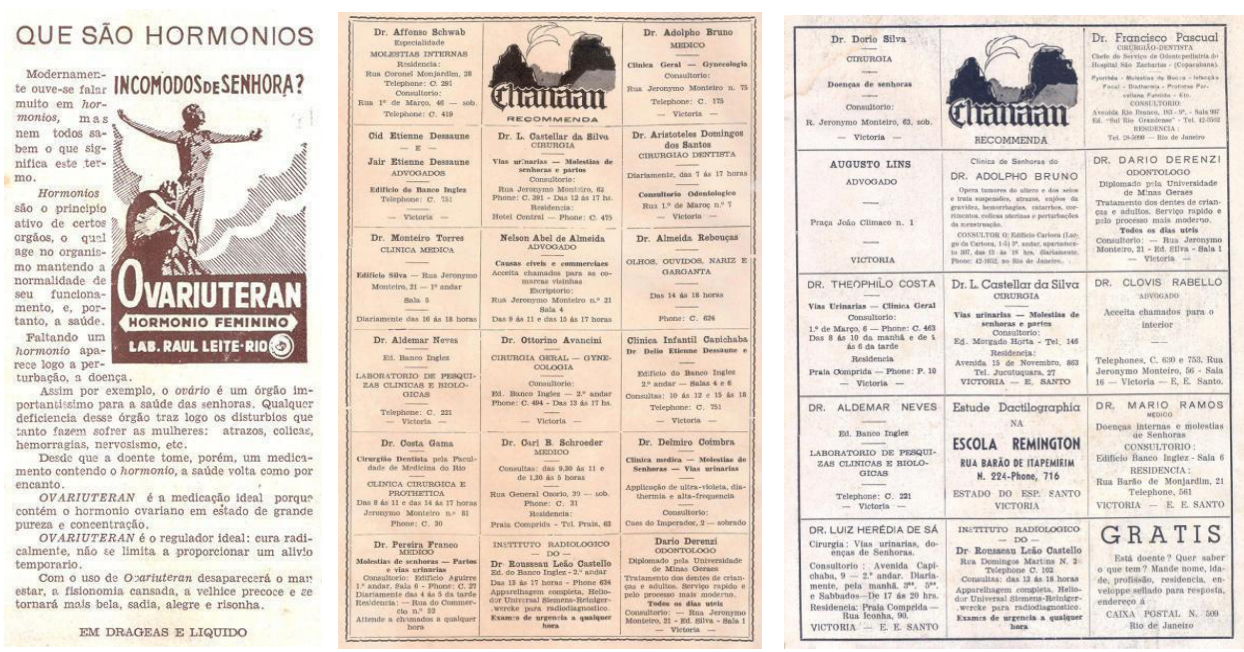

Fonte: Chanaan $(1936,1939)$.

\subsection{Publicação de Imagens}

Na revista Chanaan, assim como a quantidade de páginas e anúncios oscilavam com frequência ao longo das edições, a quantidade de imagens também variava, o mínimo foi com 28 imagens e o máximo com 120, diversificando entre fotografias, ilustrações e fotocomposições. Já a RVC, quanto às imagens, foi diferente, oscilando mais do que os anúncios e páginas, chegando a ter 5 imagens em uma edição e 67 em outra, mas variando entre 20 e 40 imagens.

Comparando as duas revistas, a Chanaan teve o uso de imagens em suas edições muito superior a RVC, nas poucas edições em que a Chanaan apresentou uma quantidade menor de imagens, ainda era um número próximo, como: 35 imagens na Chanaan e 40 na RVC nas edições de março de 1939; e 29 imagens na Chanaan e 31 na RVC em setembro do mesmo ano, porém deve ser considerado que a RVC possuía duas edições por mês e a Chanaan uma.

A diferença mais marcante entre a Chanaan e RVC é a presença de ilustrações e charges ser frequente na RVC, diferente da Chanaan. As assinaturas mais frequentes de ilustradores são do Oseas, Rogaciano Corrêa e Mario Amorim, assinando inclusive diversas capas, que como citado anteriormente, foi muito presente na RVC. 


\section{CONCLUSÃO}

A Revista Vida Capichaba era constante com as publicações das edições, ao contrário da Chanaan que ficou alguns períodos sem publicar. A constância da RVC também pôde ser verificada na quantidade de páginas, uso de tipos de papel e preço, aspectos que mudaram pouco ou não variaram. A RVC durante o período comparado era mais sóbria, mantinha um padrão com o uso de tipografias, caligrafias e letreiramentos nos textos, títulos, assinaturas e legendas, não possuindo grandes experimentos, sendo exceções à seção fixa 'Vida Capichaba' e algumas fotomontagens. Já a mancha gráfica da Chanaan variou consideravelmente, tanto nos experimentos em textos diversos e fotomontagens, quanto em tipografias, caligrafias e letreiramentos, legendas e assinaturas, sendo essas experimentações características da revista.

A sobriedade da RVC estava presente até mesmo nos anúncios, refletindo na quantidade de anúncios por edição e posicionamento deles na página, sempre seguindo o grid, diferente da Chanaan que alguns se confundiam no meio do texto.

A Chanaan publicava mais informações sobre ela do que a RVC durante esse período, como pessoas e revistas que falavam sobre a revista ou os colaboradores que escreviam, fotografavam e representavam o impresso, porém as duas continham anúncios delas mesmas.

$\mathrm{Na}$ Chanaan, Punaro Bley tinha grande destaque, tanto para os seus atos políticos como para sua vida pessoal, retratando frequentemente sua família. Já na RVC nenhum político tem grande destaque.

Através das coletas de dados, análises gráficas e comparações entre as duas revistas foi possível reconhecer os recursos gráficos do período, contribuindo para a construção de um material de consulta e com a memória gráfica capixaba. 


\section{REFERÊNCIAS}

ACHIAMÉ, Fernando. O Espírito Santo na Era Vargas (1930-1937): elites políticas e reformismo autoritário. Vitória: FGV, 2010.

AZERÊDO, Júlia Sousa; TOSO, Aline; PEDRUZZI, Letícia. Revista Chanaan e a memória gráfica capixaba. Blucher Design Proceedings, São Paulo, v. 2, n. 2, p. 1606-1612, 2015.

CHANAAN. Vitória, ES: Imprensa Official. 1936-1939. Mensal.

DUTRA, Thiago Luiz Mendes; FONSECA, Letícia Pedruzzi. Metodologia de análise gráfica do Jornal Posição: otimização de processos em pesquisas relacionadas à memória. Blucher Design Proceedings, São Paulo v. 1, n. 2, p. 1748-1753, 2014.

DUTRA, Thiago Luiz Mendes; FONSECA, Letícia Pedruzzi; PACHECO, H. S. A revista Vida Capichaba no seu contexto histórico. Revista Tipo \& Grafia, Vitória, ES, v. 1, n. 1, p. 4-8, 2011.

MATTEDI, José Carlos. História da Imprensa Oficial do Espírito Santo. Vitória, 2005.

VIDA CAPICHABA. Vitória, ES: Imprensa Estadual, 1923-1960. Mensal. 